\title{
RESEARCH HIGHLIGHTS
}

\section{ATMOSPHERIC SCIENCE}

\section{Aircraft spy on tropical storms}

Aircraft flying over tropical oceans could significantly improve the accuracy of storm forecasts by making high-resolution atmospheric measurements.

Jennifer Haase at the Scripps Institution of Oceanography in La Jolla, California, and her team developed an airborne Global Positioning System device, which uses radio signals to sense and precisely locate atmospheric conditions. In 2010, during research flights into the storm cell over the Caribbean Sea that developed into Hurricane Karl, the team found that their system agreed with data from spaceborne systems, and it increased the number of atmospheric profiles taken in the storm region by more than $50 \%$. If deployed on commercial aircraft, the technique could produce huge amounts of data for use in meteorology, the authors note. Geophys. Res. Lett. http://doi. org/rzd (2014)

\section{ZOOLOGY}

\section{How squid control} their shine

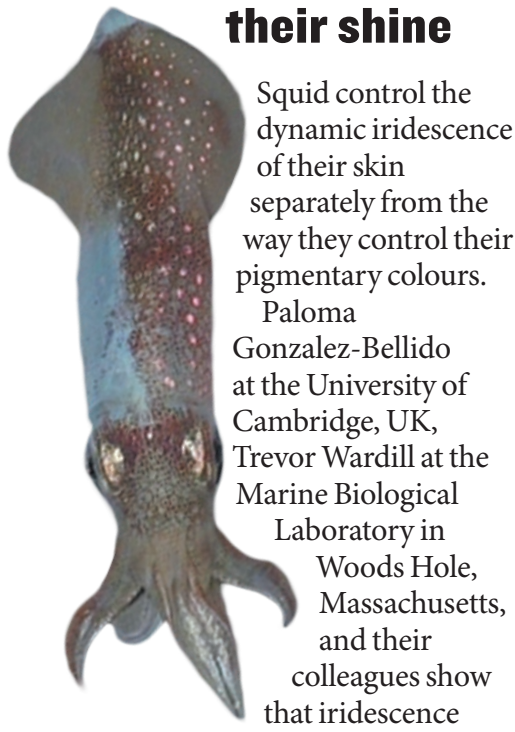

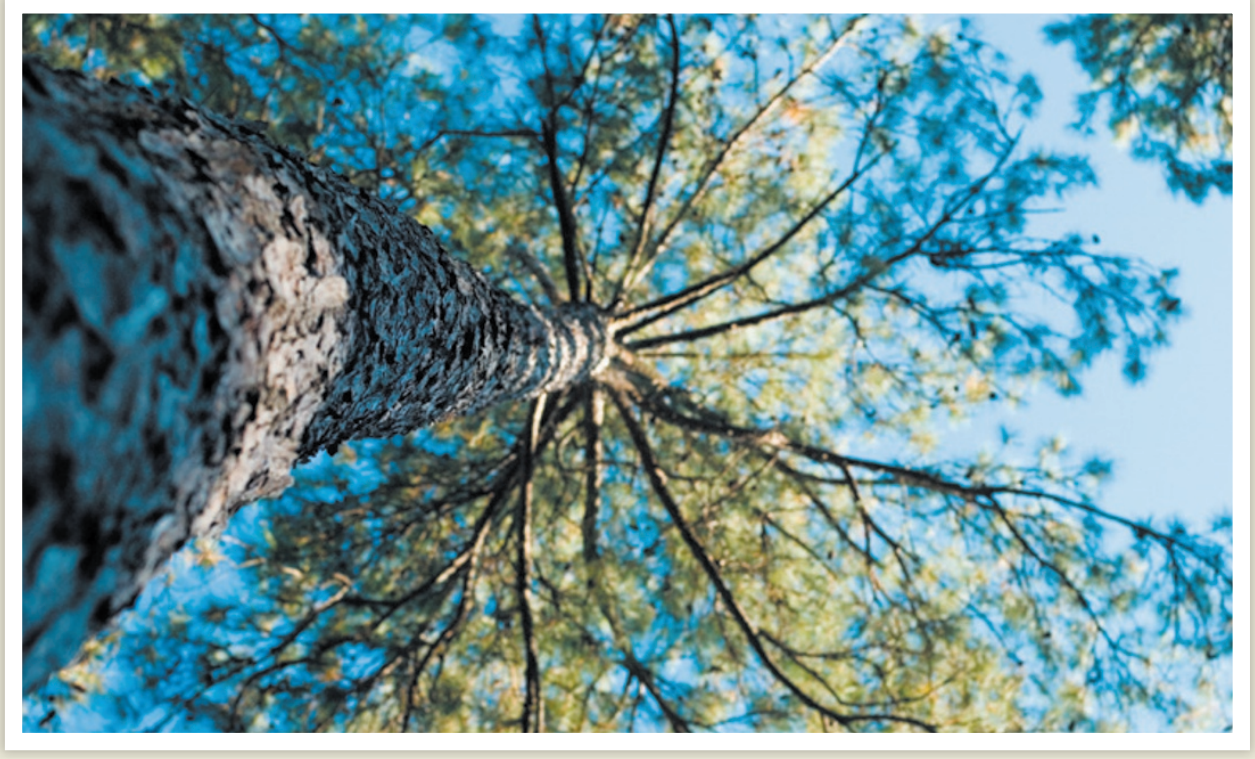

\section{GENETICS}

\section{Loblolly takes genome size prize}

A species of pine tree native to the southeastern United States has a genome with 23 billion base pairs, more than 7 times the length of the human genome.

Kristian Stevens at the University of California in Davis and his team sequenced and assembled the genome of the loblolly pine (Pinus taeda; pictured), mainly using the tissue from a single pine seed.
Another team, made up of many of the same researchers and led by Jill Wegrzyn at the University of Connecticut in Storrs, characterized around 50,000 of the genes and estimated that $82 \%$ of the loblolly genome is made from repetitive elements. This work, the first pine genome assembled so far, provides a foundation to study the biology of conifers, the authors say. Genetics 196, 875-890; 891-909 (2014) in Atlantic longfin squid (Doryteuthis pealeii) is partly controlled outside the brain through the stellate ganglion. Severing input to this ganglion on one side of the body results in the loss of iridescence on that side (pictured) within 10 minutes, with the structures responsible for this iridescence becoming transparent. Both iridescence and the control of pigmentary colours require input from the brain through the pallial nerve, but the iridescence signal is routed through the stellate ganglion. By contrast, the signals for skin-pigment changes are controlled separately through the fin nerve.

J. Exp. Bio. 217, 850-858 (2014)

\section{MATERIALS}

\section{Strong, stiff and shell-like ceramic}

A ceramic material created using ice crystals as a template has demonstrated a rare combination of high strength, toughness and stiffness.

Sylvain Deville of the French National Centre for Scientific Research in Cavaillon and his colleagues made the material from alumina platelets, alumina nanoparticles and a silicacalcia glass. When they froze the material, ice crystals grew that caused the platelets to align into layers, trapping the nanoparticles between them. These layers can be pressed and sintered into pieces a few centimetres in diameter and a few millimetres thick. Under the microscope this material resembles nacre, which makes up many seashells, and is as strong and tough as many aluminium alloys used in engineering, but with higher hardness and stiffness, which it maintains up to $600^{\circ} \mathrm{C}$. Nature Mat. http://doi.org/r29 (2014) 